\title{
A SCALE OF GRADE AND CLASS TERMS FOR CLASTIC SEDIMENTS ${ }^{x}$
}

\author{
CHESTER K. WENTWORTH \\ State University of Iowa
}

INTRODUCTION

CONTENTS

The Grade Terms

Fragment Terms

Aggregate Terms

Rock Terms

The Class Terms

\section{INTRODUCTION}

In no other science does the problem of terminology present so many difficulties as in geology. With the growth of knowledge in any field of investigation, men devise new terms or redefine old ones in the attempt to convey more precise and definite ideas. In all the branches of science much confusion has followed the redefinition of old terms because of the indiscriminate use of the terms both in the old and the new senses. But in geology, difficulties of this kind are peculiarly great.

Because geology is a field science and has followed in the footsteps of exploration, it has acquired terms from all parts of the world. Many of the names for the less common special features have come from the dialect or colloquial speech of that part of the world where they are best developed. With the use of these terms of geologists of other regions, much irregularity of usage and hence much confusion has arisen.

Since 1917, the writer had been engaged in the study of abrasion and shaping of cobbles and pebbles by the action of running water. In the course of this study the loose usage of cobble, pebble, and related terms (in which his own practice was no exception) has impressed him with the need of greater uniformity of usage and

I Published by permission of the Director of the United States Geological Survey. 
more careful definition of such terms. With this need in mind, he sent to about sixty of his colleagues of the United States Geological Survey a questionnaire asking them to give the limiting dimensions in their conception or usage of the terms bowlder, cobble, pebble, sand grain, and clay particle. Replies were received from about thirty of the men. These were studied and compared and the composite results presented in preliminary unpublished form which was distributed to more than one hundred geologists throughout the country in the hope of receiving additional comment and criticism. A small number of very helpful replies were received and utilized in modifying, to some extent, the size limits and the terms used.

Early in 1921, mimeographed copies of this modified scheme of terms were sent to about a dozen geologists in this country and England who were known as workers in the field of sediments and sedimentary rocks, and deemed competent to criticize the usages proposed. They were asked to reply to specific questions in regard to the terms which had been subject to the most criticism and to comment in general upon the plan. The replies from this smaller group were most gratifying, since nearly every geologist addressed sent a reply which the writer found useful in the preparation of the classification here presented.

In addition to the studies mentioned above, the writer commenced in 1920 the collection of definitions of sedimentary rock terms. These definitions are taken verbatim from textbooks, dictionaries, encyclopedias, and glossaries. They are typewritten on cards with the proper references and filed under the name of the term defined. Many of the definitions collected are from sources seventy-five to one hundred years old and represent the former usage of certain terms as understood by the compiler. The definitions collected in this way vary greatly in value and none is to be regarded as of absolute authority. They constitute, however, part of the data of the problem.

As will appear from the foregoing, the writer has compiled the present scheme of classification in part from a specific study of the terms here presented and in part from the results of a general consideration of terms in the field of sedimentary rocks. $\mathrm{He}$ is 
indebted to a large number of geologists who have helped him by spoken and written criticism. Space will permit acknowledgment of gratitude only to Dr. M. I. Goldman and to Dr. J. B. Woodworth, whose interest and frank criticism have been especially helpful in the preparation of this paper.

\section{THE GRADE TERMS}

It is the writer's purpose here to suggest terms which are specific as regards size of piece and, at least for the larger pieces, as regards shape of piece. The terms of this scheme apply to rounded materials in so far as materials of the size in question become rounded by transportation. Strict uniformity in this regard will not fit the sediments as they occur in nature. Bowlders, cobbles, and pebbles are rounded rock fragments, whereas most clay particles are angular, yet geologists will recognize that they all belong to a natural series. Likewise, bowlders and clay particles are not commonly of the same mineral composition but in spite of this fact they are the two extremes of the series of transported rock fragments. By an excessive multiplication of terms it would be possible to make a classification in which each term was specific as to size of particle, shape of particle, lithologic character, and other characteristics. Such a scheme would be highly artificial in many of its categories and seems to the writer impracticable in the present state of knowledge.

The present scheme of grade terms is, accordingly, just what its name implies - a series of names for clastic fragments of different sizes. They apply only to rounded fragments except in the case of fine sands, silts, and clays in which even prolonged transportation does not always round the pieces. The names applied to the different grades carry no lithologic, mineralogic, or chemical significance so far as the present scheme is concerned. Sands are dominantly quartzose, whereas clays are largely made up of kaolin, but this fact is incidental and not necessary in the use of the terms.

\section{FRAGMENT TERMS}

Bowlder.-This term is in common use in English-speaking countries for rounded and smoothed masses of rock larger than 
cobbles $^{\mathrm{x}}$ resulting from abrasion in transportation. Angular masses of rock of the same size are commonly called blocks or slabs. The word bowlder is related to the English word bellow; compare Swedish bullra, to rattle or roar. Equivalent terms in several other languages carry similar ideas of rumbling or rolling in their derivation.

Cobble.-Cobble or cobblestone is used generally, both by geologists, and in common speech, for a rounded stone smaller than a bowlder and larger than a pebble. The term is a diminutive of the word $c o b$, meaning a rounded hump or knob, and related to the German Kopf, for head.

Pebble.-This term is a very ancient one which is used commonly for rounded, transported rock fragments smaller than cobbles. In the past it was more commonly used than it is at present for rounded stones up to the size of bowlders. The tendency now is to use the term cobble in an intermediate sense, as stated above. Pebble is from the Anglo-Saxon papol, which meant something small and round, perhaps akin to the Latin papula, a pustule.

Gramule. ${ }^{2}$-The term granule is here proposed by the writer as a term for rounded rock fragments larger than very coarse sand grains but smaller than pebbles. Rounded pieces too small to be called pebbles have still been too large to be called sand grains in the practice of most geologists. Granule is from the Latin granulum, diminutive of granum, grain, meaning a little grain, a pellet. In spite of apparent infelicity of meaning (little grain), this term was chosen as best adapted for this grade of material. The term grit grain was considered for use in this sense, but was thought less satisfactory. Grit is used in another sense, as for fine sandstone of angular grain. It seemed undesirable to include these grains either with small pebbles or with coarse sand grains, and it is hoped that the term granule may fill an apparent gap in the series of terms heretofore used.

Sand grain.-The several terms made up by the use of adjectives qualifying sand grain are self-explanatory.

${ }^{I}$ For explanation of the basis on which the sizes limiting the several grades were chosen, see the text which follows.

${ }_{2}$ This term was suggested to the writer by Dr. Herbert A. Baker, of England. 
Silt particle.-The term silt particle is here applied to individual particles smaller than very fine sand grains but larger than clay particles. The term silt from which it was derived was objected to by some geologists on grounds that are stated under the heading of silt. These grounds were not sustained even by a minor part of the data available to the writer and the term is here used as the most satisfactory one.

TABLE I

The Grade Terms

\begin{tabular}{|c|c|c|}
\hline The Pieces & The Aggregate & The Indurated Rock \\
\hline Bowlder & Bowlder gravel & Bowlder conglomerate \\
\hline${ }^{250 \mathrm{~mm} .}$ & Cobble gravel & Cobble conglomerate \\
\hline${ }^{64 \mathrm{~mm} .}=$ & Pebble gravel & Pebble conglomerate \\
\hline $4 \mathrm{~mm} . \overline{\text { Granule }}$ & Granule gravel & Granule conglomerate \\
\hline $\begin{array}{l}2 \mathrm{~mm} . \\
\text { Very coarse sand grain }\end{array}$ & Very coarse sand & Very coarse sandstone \\
\hline $\begin{array}{l}\text { I mm. } \\
\text { Coarse sand grain }\end{array}$ & Coarse sand & Coarse sandstone \\
\hline $\begin{array}{l}\text { I } / 2 \mathrm{~mm} . \\
\text { Medium sand grain }\end{array}$ & Medium sand & Medium sandstone \\
\hline $\begin{array}{l}\mathrm{I} / 4 \mathrm{~mm} . \\
\text { Fine sand grain }\end{array}$ & Fine sand & Fine sandstone \\
\hline $\begin{array}{l}\mathrm{I} / 8 \mathrm{~mm} . \\
\text { Very fine sand grain }\end{array}$ & Very fine sand & Very fine sandstone \\
\hline $\begin{array}{l}\text { I / } 16 \mathrm{~mm} .-\overline{\text { Silt particle }} \\
\text {. }\end{array}$ & Silt & Siltstone \\
\hline $\begin{array}{l}\text { I } / 256 \mathrm{~mm} . \\
\text { Clay particle }\end{array}$ & Clay & Claystone \\
\hline
\end{tabular}

Clay particle.-After consideration of several other terms for the materials finer than silt, the term clay was finally adopted as most likely to meet with general approval. Clay particle is therefore used for the individual pieces.

The size limits.--In fixing the limiting sizes of the several grades of the scheme shown in the table, the writer has been governed by two considerations. First, there is a growing acceptance among geologists and engineers of a series of sieves for the classification of natural clastic materials in which the openings of consecutive size stand to one another in the ratio 2 or $\sqrt{2}$ starting with I $\mathrm{mm}$. as the standard. 
It has long been recognized that the differences between two consecutive screen size openings should be greater for the large sizes than for the small. This principle is followed in the selection of such limits as I, 2, 5, 10, 20 millimeters, making the limits fall on convenient whole numbers in the decimal notation. This series, however, is a crude approach to a geometrical series in which each value bears a constant ratio to the preceding one. A geometrical series is the ideal for such a purpose, since a change of $\mathrm{I}^{\prime \prime}$ is of the same significance and importance in the size of $\mathrm{IO}^{\prime \prime}$ cobbles as a change of $\frac{1}{10}$ " in the size of $I^{\prime \prime}$ pebbles. Only by the use of logarithmic or some similar graphical scheme of representation can the size composition data be shown adequately for great size ranges. The use of a geometrical series makes the successive grades fall into equal units on the graph-an arrangement much easier to read and interpret than any other known to the writer. The most convenient ratio for the construction of such a series is the ratio 2 , and the most convenient and logical starting-point, I $\mathrm{mm}$. A large number of mechanical analyses of sediments made with screens and by microscopic measurement conforming to such a series have been made. ${ }^{\text {If }}$ a more minute subdivision is needed, the ratio $\sqrt{2}$ can be used, giving twice the number of grades, or in exceptional cases $\sqrt[4]{2}$. These extra subdivisions fit in with and form further subdivisions of the fundamental series of the powers of 2. Conformity to this geometrical series is the first consideration which has guided the writer in fixing the limits between the several grade terms.

The second consideration has been the desire to make each of the limits as close as possible to the common practice of the majority of geologists. Figure I shows the composite opinions of twentyeight geologists of the United States Geological Survey, as reported by them in response to a questionnaire on the sizes limiting several of the terms. The table below shows a number of different schemes of classification which have been published. There is a close agreement between some of those shown, but, with the exception of that of Udden, all lack, in the sizes of successive grades, the uniformity

s J. A. Udden, "Mechanical Composition of Clastic Sediments," Bull. Geol. Soc. Amer., Vol. XXV (1914), pp. 655-744. 
of ratio of the geometrical series which seems to the writer to be essential to any thorough quantitative study of the mechanical composition of sediments.

Using the data shown in Figure $\mathrm{I}$ and Table II, the writer has selected the limits conforming to the power series of 2 which most closely conform also to the concensus of the opinions

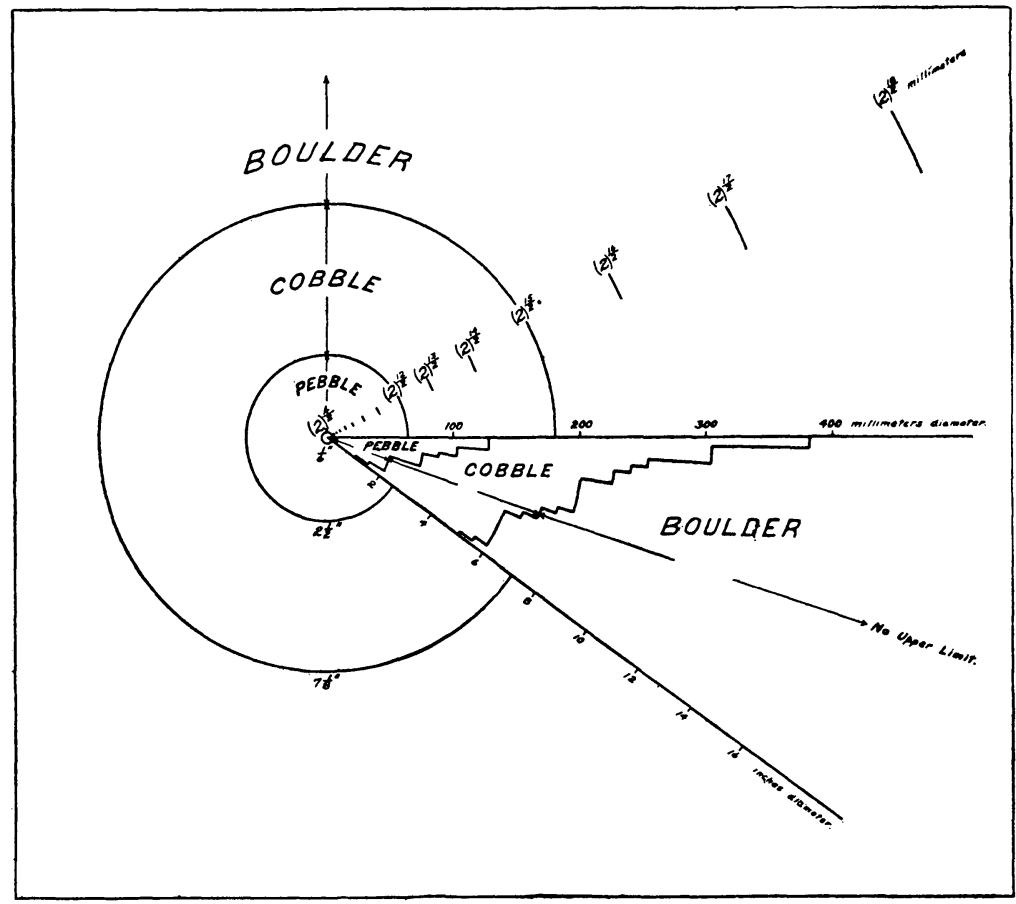

FIG. I

of authorities quoted there. The names of the several grades thus established were then chosen as described above.

AGGREGATE TERMS

The assignment of definite limiting size values to the terms for the aggregates as named below, as well as the rocks named in another part of this paper, will be objected to on the ground that aggregates are not made up in nature of one grade or even of a few grades, and that therefore the names are inapplicable. The author 


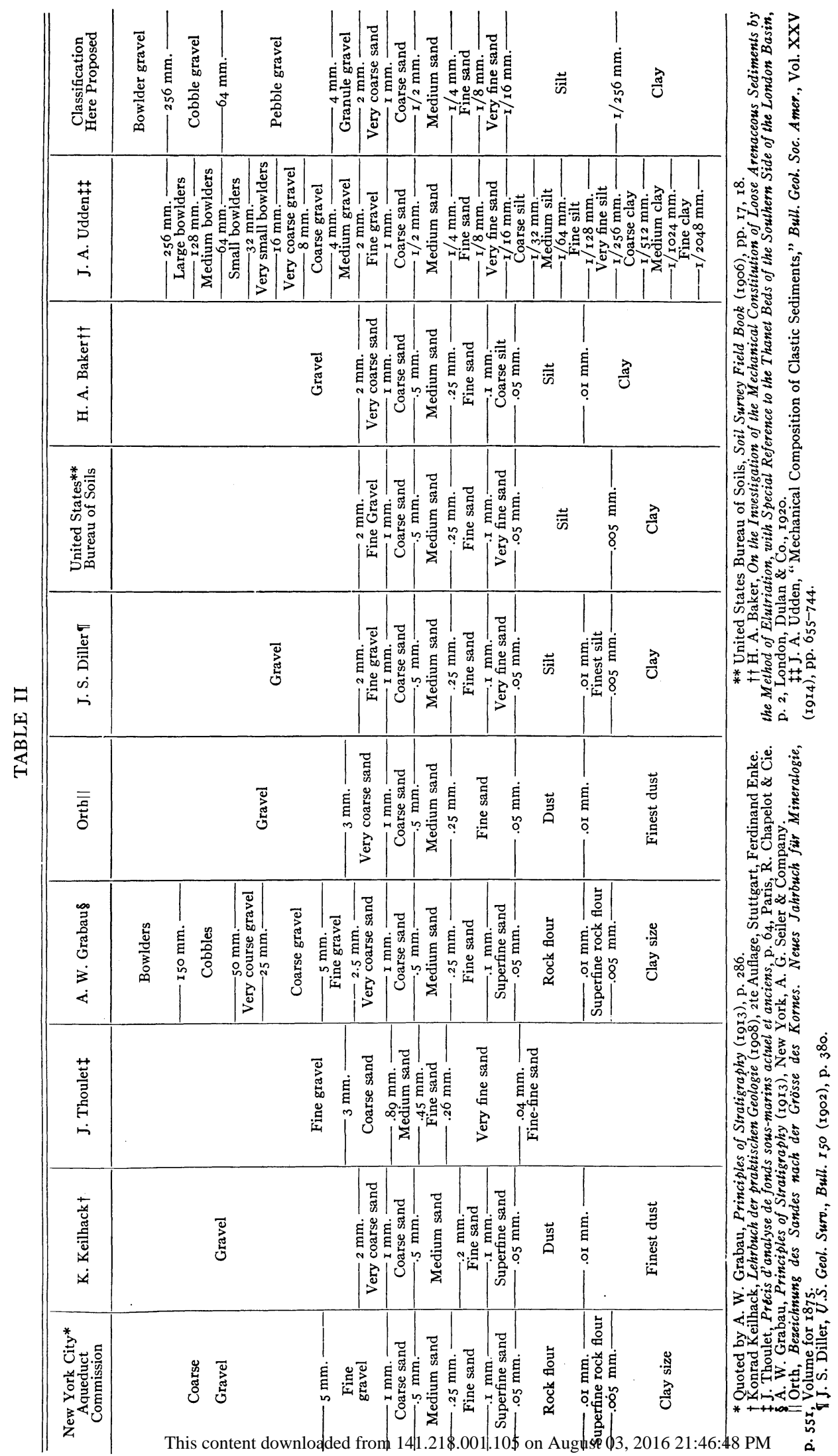

All use subject to University of Chicago Press Terms and Conditions (http://www.journals.uchicago.edu/t-and-c). 
recognizes this difficulty and the grade terms here defined are applicable strictly and without modification to but few natural sediments. They are proposed as the foundation of, and in the course of development of, the several class terms and adjectives proposed in the last part of this paper. Photographs of grade aggregates from $64 \mathrm{~mm}$. to $\frac{1}{32} \mathrm{~mm}$. are shown in the accompanying Figures 2 and 3.

Gravel.-Among some geologists the term gravel has been used only for material composed of small pebbles and granules, but more commonly and especially in America and in reference to glacial gravels, the term has been used to include material containing great bowlders up to a meter or more in diameter, and has recently been so defined by J. S. Flett ${ }^{\mathrm{x}}$ who considers the term to be the equivalent of conglomerate as applied to the consolidated rocks. It is in this latter and prevailing sense that the term is here used and combined with qualifying words in the terms bowlder gravel, cobble gravel, pebble gravel, and granule gravel.

Sand.-The term sand is in common use among all Englishspeaking geologists for mineral grains smaller than I or $2 \mathrm{~mm}$. and larger than silt. By some writers, sand is applied only to rounded mineral grains, but others use the term more generally. Sand is from the Anglo-Saxon word of the same spelling and meaning.

Silt.-The term silt is considered by some geologists to apply properly to deposits containing organic matter in addition to the mineral particles. The writer was unable to find any considerable support of this view by either past or present authorities, and has here used the term for the grades designated in the table on page 384. The word silt is probably akin to a number of Germanic roots meaning to sift or filter, compare German seihen, to strain.

Clay.-After consideration of a number of alternative terms, the term clay has been selected as most likely to be acceptable to geologists for the finest clastic sediments. A few geologists objected to the term on the ground that it implied plasticity or that it referred to a definite chemical composition. It is the view

× J. S. Flett, Encyclopaedia Britannica, IIth ed. (I9II), Vol. XII, p. 382, and Vol. VI, p. 9r3. 


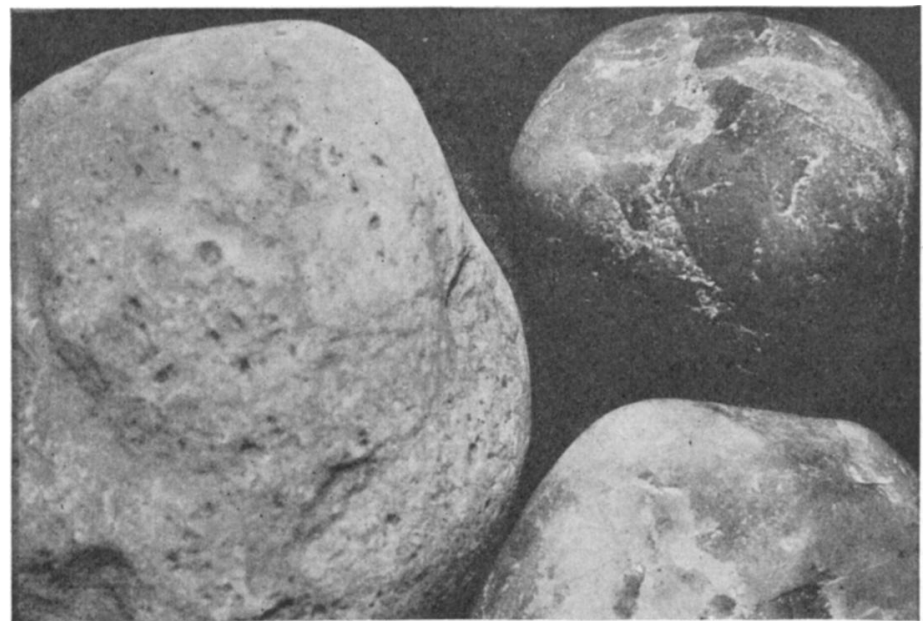

$64-32 \mathrm{~mm}$

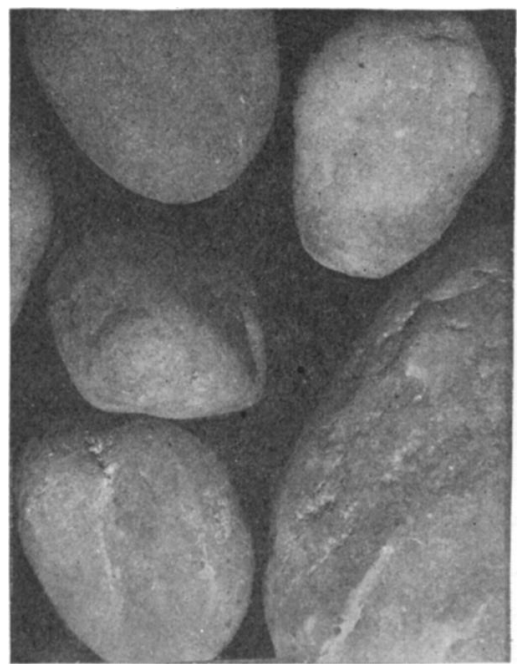

$32-\mathrm{r} 6 \mathrm{~mm}$

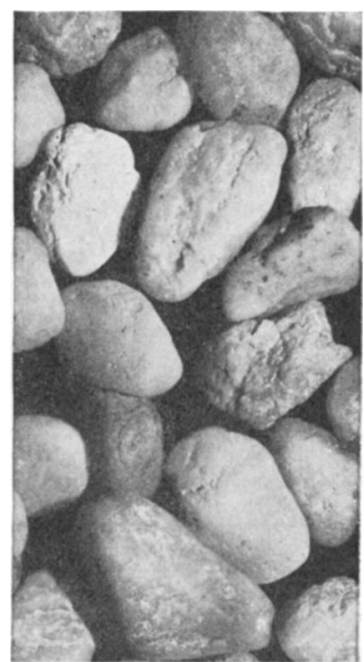

$16-8 \mathrm{~mm}$

Pebble gravel

Natural Size

FIG. 2

This content downloaded from 141.218.001.105 on August 03, 2016 21:46:48 PM All use subject to University of Chicago Press Terms and Conditions (http://www.journals.uchicago.edu/t-and-c). 
of the writer and of many other geologists that nearly all clastic materials of this grade consist largely of the hydrous aluminum silicates which make up the clay of the chemist and also that the material is always more or less plastic. There is, therefore, in his opinion a common ground for the geologist and chemist without an insistence on the use of the term clay for the pure chemical compounds kaolin or other minerals of this group.

\section{ROCK TERMS}

Conglomerate.-There are certain terms which are used with greater uniformity and less abuse than others. One of these is conglomerate. This term is very widely applied to rocks which are the consolidated equivalents of gravels. It is applied just as is the term gravel to rocks which vary widely in the sizes of their constituent particles. It seems desirable, therefore, to apply to it modifying adjectives as has been done with gravel, making the terms bowlder-conglomerate, cobble-conglomerate, pebble-conglomerate, and granule-conglomerate. The term granule-conglomerate is preferred to the term grit because grit has been used in England for both coarse- and fine-grained and angular-grained sandstones. The use of the term grit in the present sense seems therefore inadvisable.

Sandstone.-This term is generally used by geologists and no great change in its usage is here proposed. It is qualified by the adjectives very coarse, coarse, medium, fine, and very fine, and used for the consolidated equivalents of the various grades of sand. The term grit is not used for the coarser grade for the reasons stated in considering the term granule-conglomerate.

Siltstone.-After a consideration of a number of terms, siltstone was adopted by the writer as most acceptable for the consolidated equivalent of a silt. Shale, as proposed by some geologists, was considered objectionable because, in the usage of a majority of geologists at present, as well as etymologically, it is a structural term referring to the shelly structure of the rock rather than to the size of its grains.

Claystone.-The term argillite has already been used in another sense and the term shale is objectionable for the reasons given 


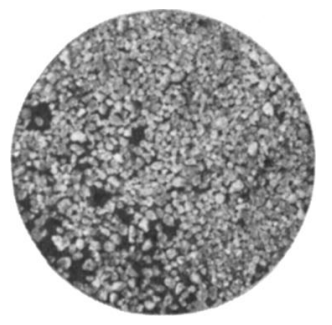

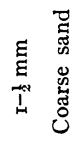
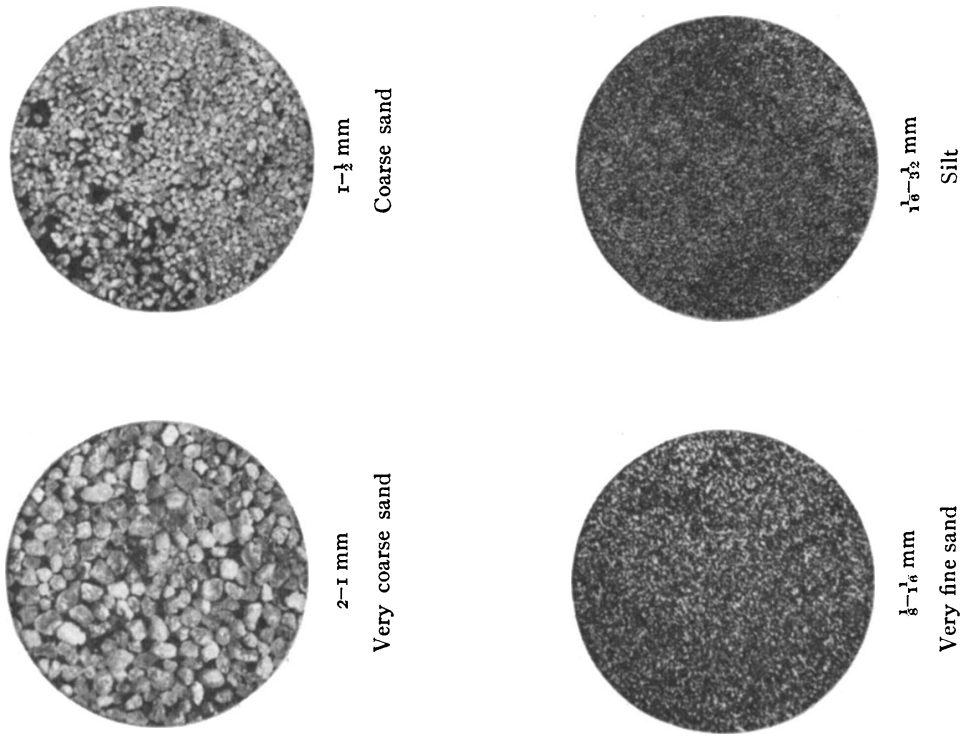

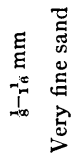

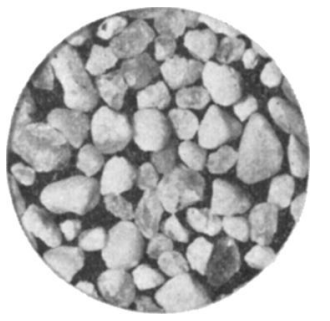

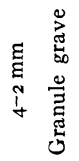

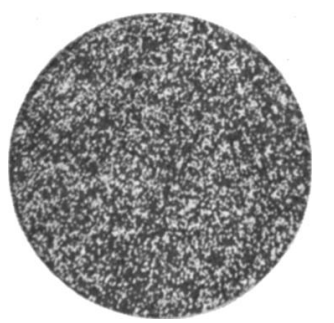

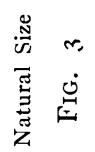

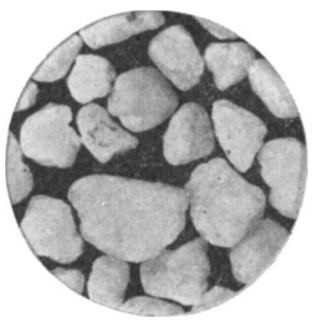

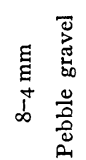

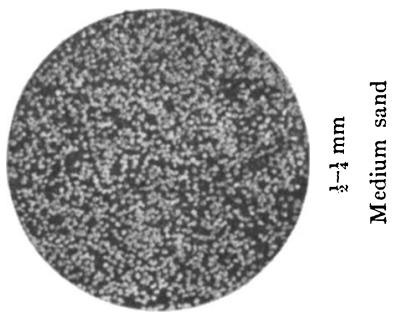

This content downloaded from 141.218.001.105 on August 03, 2016 21:46:48 PM All use subject to University of Chicago Press Terms and Conditions (http://www.journals.uchicago.edu/t-and-c). 
above. The term claystone is here proposed as most satisfactory for the indurated equivalent of clay, as defined above.

\section{THE CLASS TERMS}

The grade terms defined above for aggregates and for rocks are applicable, as the writer has pointed out in another part of this paper, to very few sediments of natural origin. Most such sediments are composed of particles of several or many grades and the names suggested above with definite numerical limits cannot properly be applied to them. This difficulty has been long recognized by students of sedimentary rocks and several schemes for meeting the difficulty have been proposed. Notable among these, because of the large amount of data published in accordance with it, is that of the United States Bureau of Soils which is given below.

\section{CLASSIFICATION OF SOIL MATERIAL}

\section{United States Bureau of Solls*}

Soils containing $20 \%$ silt and clay:

Coarse sand ....... more than $25 \%$ very coarse sand and coarse sand and less than $50 \%$ any other grade

Sand ...........more than $25 \%$ very coarse sand, coarse and medium sand, and less than $50 \%$ fine sand

Fine sand .........more than $50 \%$ fine sand, or less than $25 \%$ very coarse sand, coarse and medium sand

Very fine sand...... more than $50 \%$ very fine sand

Soils containing $20-50 \%$ silt and clay:

Sandy loam ........ more than $25 \%$ very coarse sand, coarse and medium sand

Fine sandy loam....more than $50 \%$ fine sand or less than $25 \%$ very coarse sand, coarse and medium sand

Sandy clay........ less than $20 \%$ silt

Soils containing more than $50 \%$ silt and clay:

Loam ........... less than $20 \%$ clay, less than $50 \%$ silt

Silt loam.......... less than $20 \%$ clay, more than $50 \%$ silt

Clay loam ....... $20-30 \%$ clay, less than $50 \%$ silt

Silty clay loam . . . . 20-30\% clay, more than $50 \%$ silt

Clay .............more than $30 \%$ clay

* C. C. Fletcher and H. Bryan, "Modification of the Method of Mechanical Soil Analysis," U.S. Dept. of Agric., Bur. Soils, Bull. No. 84 (1912). 
The scheme of class terms presented below was devised by the writer after a somewhat extensive consideration of several more complicated classifications. These were characterized by more extensive use of the adjectives coarse and fine and by the use of many combinations and permutations of several grade terms.

These were all rejected in favor of the simpler plan here presented because of the seeming futility of attempting to make detailed quantitative discriminations by use of a verbal scheme. Such discrimination can be satisfactorily made only by graphic or tabular methods and the writer believes the simpler classification will be most generally acceptable and therefore most useful in the study of sediments.

The table shows only class terms for aggregates; the proper rock terms will be chosen and used in an analogous manner.

Class Terms for Sediments

Specifications by Grade
Gravel $>80 \%$
Gravel $>$ sand $>10 \%$
Sand $>$ gravel $>10 \%$
Sand $>80 \%$
Sand $>$ silt $>10 \%$
Silt $>$ sand $>10 \%$
Silt $>80 \%$
Silt $>$ clay $>10 \%$
Clay $>$ silt $>10 \%$
Clay $>80 \%$

$\begin{array}{ll} & \text { Terms for Classes } \\ \text { Gravel } \\ \text { Others }<10 \% & \text { Sandy gravel } \\ \text { Others }<10 \% & \begin{array}{l}\text { Gravelly sand } \\ \text { Sand }\end{array} \\ \text { Others }<10 \% & \text { Silty sand } \\ \text { Others }<10 \% & \text { Sandy silt } \\ & \text { Silt } \\ \text { Others }<10 \% & \text { Clayey silt } \\ \text { Others }<10 \% & \text { Silty clay } \\ & \text { Clay }\end{array}$

Certain materials of sedimentary origin but highly variable composition, notably glacial till, will not fall into any of the divisions of the table above. No attempt has been made to make an all-inclusive scheme. Till is known by its extreme range of mechanical composition and by definition, there core, will not fit into so simple a classification. The test of any classification is in its applicability to natural objects. The terms here proposed were tested by reference to a large number of analyses made by Udden. ${ }^{\mathrm{x}}$ By inspection of about fifty of these chosen at random it was found that only the analyses of till did not accord with the specification given for one of the terms, and that each of the other

${ }^{\mathrm{I}} \mathrm{J}$. A. Udden, loc. cit. 
sediments tested was assigned to a suitable name differing only in added exactness from that used in the original description. In the table below are given nine of these analyses showing the

Table of Mechanical Analyses by J. A. Udden* Showing the Sediment Names Appropriate to the Classification of This Paper

\begin{tabular}{|c|c|c|c|c|c|}
\hline Diameter in Millimeters & $\begin{array}{l}\text { No. } 75 \dagger \\
\text { Gravel } \dagger\end{array}$ & $\begin{array}{c}\text { No. } 9 \\
\text { Sandy Gravel }\end{array}$ & $\begin{array}{c}\text { No. I8 } \\
\text { Gravelly Sand }\end{array}$ & $\begin{array}{l}\text { No. r6 } \\
\text { Sand }\end{array}$ & $\begin{array}{l}\text { No. } 68 \\
\text { Silty Sand }\end{array}$ \\
\hline $64-32 \ldots \ldots \ldots \ldots$ & . & .2 & & 1. & $\cdots$ \\
\hline $3^{2-16 \ldots \ldots \ldots \ldots}$ & $\ldots \ldots$ & 14.0 & & $\cdots$ & $\cdots$ \\
\hline 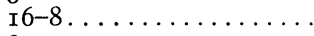 & $3 \cdot 3$ & $\mathrm{I} 3.2$ & $\ldots$ & $\ldots$ & $\cdots$ \\
\hline $8-4 \ldots \ldots \ldots \ldots \ldots$ & $65 \cdot 9$ & 20.0 & 6. I & $\ldots \ldots \ldots$ & $\ldots \ldots \ldots$ \\
\hline $4-2 \ldots \ldots \ldots \ldots \ldots \ldots$ & 26.0 & $\mathrm{r} 4.4$ & $7 \cdot 4$ & I. 7 & .2 \\
\hline $2-I \ldots \ldots \ldots \ldots$ & 3.0 & I I . 4 & 3.6 & $24 \cdot 4$ & $\cdot 3$ \\
\hline$I-I / 2 \ldots$ & .3 & 18.2 & 7.2 & 49.2 & 7.2 \\
\hline $\mathrm{I} / 2-\mathrm{I} / 4$ & .2 & 5.6 & 36.8 & 8.3 & I 7.9 \\
\hline $\mathrm{I} / 4-\mathrm{I} / 8 \ldots$ & .7 & 2.6 & $37 \cdot 4$ & I4. 8 & 48.7 \\
\hline $\mathrm{I} / 8-\mathrm{I} / \mathrm{r} 6 \ldots$ & .3 & .2 & I. 2 & I.O & 8.4 \\
\hline$I / I 6-I / 32 \ldots$ & $\ldots$ & $\ldots$ & .2 & .4 & I 3.2 \\
\hline $\mathrm{I} / 32-\mathrm{I} / 64$ & $\ldots$ & $\ldots$ & $\ldots$ & .1 & 3.2 \\
\hline $\mathrm{I} / 64-\mathrm{I} / \mathrm{I} 28$ & . & . & & $\ldots$ & .7 \\
\hline $\mathrm{I} / \mathrm{I} 28-\mathrm{I} / 25^{6} \ldots \ldots$ & . . & $\ldots \ldots$ & . & $\ldots \ldots$ &. $\mathrm{I}$ \\
\hline
\end{tabular}

* J. A. Udden, loc. cit.

$\dagger$ The numbers are those used by Udden in describing these sediments. The names are applied by the author of this paper according to the terminology here presented.

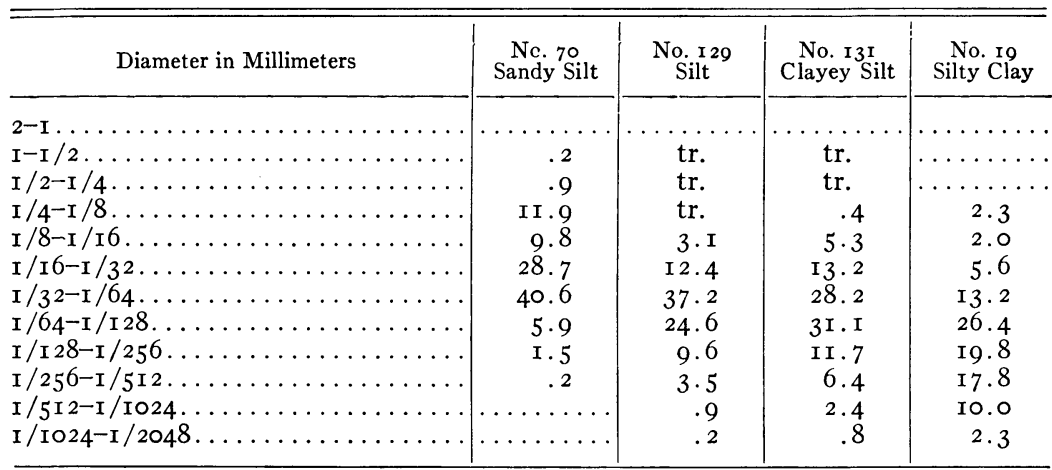

composition, the number in Udden's table, and the name according to the present classification.

It will be pointed out that in order to name a sediment, one must first make a mechanical analysis. This is true to the degree 
that it is true that microscopic study precedes the final naming of an igneous rock. However, as in the case of igneous rocks, field names based on simple megascopic inspection will be extensively used before detailed studies are made. It is believed that field names can be more accurately and expressively used if the principles and essential facts of a quantitative classification such as that here proposed are duly recognized. 